\title{
Testing of SMA-enabled active chevron prototypes under representative flow conditions
}

\author{
Travis L. Turner ${ }^{*}$, Randolph H. Cabell ${ }^{* *}$, Roberto J. Cano ${ }^{\dagger}$, and Richard J. Silcox ${ }^{*}$ \\ NASA Langley Research Center, Hampton, VA USA 23681-2199
}

\begin{abstract}
Control of jet noise continues to be an important research topic. Exhaust-nozzle chevrons have been shown to reduce jet noise, but parametric effects are not well understood. Additionally, thrust loss due to chevrons at cruise suggests significant benefit from active chevrons. The focus of this study is development of an active chevron concept for the primary purpose of parametric studies for jet noise reduction in the laboratory and secondarily for technology development to leverage for full scale systems. The active chevron concept employed in this work consists of a laminated composite structure with embedded shape memory alloy (SMA) actuators, termed a SMA hybrid composite (SMAHC). SMA actuators are embedded on one side of the neutral axis of the structure such that thermal excitation, via joule heating, generates a moment and deflects the structure. The performance of two active chevron concepts is demonstrated in the presence of representative flow conditions. One of the concepts is shown to possess significant advantages for the proposed application and is selected for further development. Fabrication and design changes are described and shown to produce a chevron prototype that meets the performance objectives.
\end{abstract}

Keywords: jet engine chevrons, active/adaptive chevrons, shape control, deflection control, jet noise control, flow effectors, flow control, shape memory alloys, Nitinol, embedded actuators

\section{INTRODUCTION}

Reduction of jet engine noise in the vicinity of airports continues to be of paramount importance. Jet exhaust-nozzle chevron systems are a proven noise reduction technology, but much is yet to be learned about their parametric design space and a tradeoff between noise reduction at takeoff/landing and thrust loss at cruise has slowed their incorporation into production engines ${ }^{[1]}$. The presence of chevrons on a nozzle produces a scalloped (serrated) trailing edge with the chevrons protruding into the flow, increasingly from root to tip, in the flow direction. All model-scale noise reduction and/or flow studies involving chevrons have been performed using static chevron technology, where the geometry and resulting flow immersion is predetermined and invariant ${ }^{[2]-[12]}$. These studies typically included some parametric investigation of chevron number, geometry, and immersion. However, detailed parametric investigations using static chevrons were not possible because of the high cost of fabricating and testing separate nozzle systems. Numerical studies are also limited for investigation of the parametric design space because current computational tools lack the aeroacoustic fidelity needed for design.

One means of simultaneously addressing some parametric design issues and the tradeoff of noise reduction and thrust penalty is the development of active (deployable) chevrons. The active chevron application appears to be ideal for shape memory alloy (SMA) actuation technology because SMA actuators can be thermally activated, they can produce large force and stroke, and the quasi-static nature of active chevron requirements alleviates issues associated with the limited frequency response of the thermoelastic shape memory effect. Shape memory alloys exhibit a phase transformation that is driven by temperature and stress. The thermally induced phase transformation is responsible for the well-known shape memory effect (SME) that is of primary interest in this study. Shape memory alloys can recover a large strain by the

\footnotetext{
*t.l.turner@.nasa.gov; phone 1757 864-3598; fax 1757 864-8823; Mail Stop 463; http://stab.larc.nasa.gov randolph.h.cabell@,nasa.gov; phone 1757 864-5266; fax 1757 864-8823; Mail Stop 463; http://stab.larc.nasa.gov $\dagger$ roberto.j.cano@nasa.gov; phone 1757 864-3951; fax 1757 864-8312; Mail Stop 226; http://smc.larc.nasa.gov/AMPB

r.j.silcox@nasa.gov; phone 1757 864-3590; fax 1757 864-8823; Mail Stop 463; http://stab.larc.nasa.gov
} 
SME when heated in an unconstrained configuration and generate large forces when strain recovery is prevented. Thus, the general concept for a SMA-enabled active chevron entails deploying the chevron under the actuation authority of prestrained SMA actuators. It is noted that the transformation temperatures of commercially available SMA materials limit their application to the bypass nozzle of typical commercial engines. A good overview of SMAs and their behavior is given by Otsuka and Wayman ${ }^{[13]}$.

SMA actuators can be employed in various ways to enable active chevrons. Research has appeared in the literature that is related to this goal. Bruck, Moore, and Valentine ${ }^{[14]}$ developed a beam bending concept involving polyurethane matrix materials with embedded and opposing one-way trained SMA actuators. Their work showed that at least $25 \%$ greater recovery strains can be achieved via opposing one-way actuation as compared to two-way actuation. They also found that inducing bending deformation by in-plane actuation was compromised by excessive compliance in the matrix material of the parent structure. Kim, Park, and $\mathrm{Goo}^{[15]}$ investigated the effects of elastic tailoring, e.g., composite ply angles, on bend and twist deformations of composite beams. The results of this numerical study indicate that large and complex bending shape changes can be achieved by exploiting coupling, i.e., bend-extension and bend-twist, stiffness of composite laminates. Chandra ${ }^{[16]}$ reported results of SMA bender elements embedded in composite beams for delivering bend and twist authority by exploiting bend-twist coupling of the composite layup. Baz, Chen, and $\mathrm{Ro}^{[17]}$ also incorporated bender elements within sleeves on the neutral axis of composite beams to control bending deflections without incurring the effects of in-plane stress.

The only SMA-enabled active chevron concept known from the literature, other than the work of the present authors, was reported by Calkins and Butler ${ }^{[18]}$ and Mabe et al. ${ }^{[19],[20]}$. The active chevron concept described in those references involved the use of Nitinol bender elements that worked against a metallic or composite main structure to provide deflection control. Previous work at NASA Langley Research Center (LaRC) has demonstrated various structural control concepts via SMA hybrid composite (SMAHC) laminates ${ }^{[21]-[23]}$. The active chevron concepts considered in this study are an extension of that work and consist of Nitinol actuators embedded on one side of the neutral axis of a laminated composite structure. Thus, thermal excitation causes the actuators to attempt recovery of the prestrain under the constraint of the bond to the host material. The resulting asymmetry in thermal stress causes a moment that deflects the structure. The aerodynamic load due to engine flow and/or the force developed in the host composite due to stored strain energy from deflection are used to restore the structure to the un-actuated configuration.

Previous work by the present authors demonstrated the feasibility of the active SMAHC chevron concept using a flat prototype, i.e., without the cylindrical radius of curvature ${ }^{[24],[25]}$. That work also provided the first experimental validation of a commercially available (MSC.Nastran and ABAQUS) constitutive model for SMAHC materials and structures for shape-control applications ${ }^{[26]-[28]}$. Recent work extended that active chevron concept to include the cylindrical radius of curvature. Bench-top test results from two prototypes, having differing actuation schemes, were presented $^{[29]}$. The objectives of the present work are to test the two curved chevron prototypes under flow conditions representative of the bypass exhaust of a typical commercial engine, down-select to a final configuration, and refine the design to meet performance objectives with flow. The longer-term objective of the project, for which this study forms a part, is to enable parametric studies in the laboratory to investigate effects such as variable immersion depth and circumferential distribution for optimal jet noise reduction. Thus, the present study focuses on chevron systems at model scale and provisions are made to thermally activate the SMA actuators via electrical current to enable active control.

\section{BACKGROUND AND PREVIOUS WORK}

A picture of a static chevron system on the core and bypass nozzles of a jet engine simulator installed in the NASA LaRC Low Speed Aeroacoustic Wind Tunnel (LSAWT) is shown in Figure 1. The model was approximately $1 / 9^{\text {th }}$ scale of a bypass ratio (BPR) 5 engine with core and bypass nozzle diameters of $12.807 \mathrm{~cm}$ and $23.922 \mathrm{~cm}$ (at the root of the chevrons), respectively. The corresponding core and bypass nozzle areas were $72.96 \mathrm{~cm}^{2}$ and $186.62 \mathrm{~cm}^{2}$, respectively. The simulator incorporated a pylon and had chevron planform dimensions of approximately $2.5 \times 4.8 \mathrm{~cm}$. The chevron thickness was constant at $0.064 \mathrm{~cm}$ and the static immersion of each chevron tip was $0.127 \mathrm{~cm}$ without flow loading effects. The geometry and static immersion of this chevron system was specified as the result of previous numerical and experimental studies. The present effort is focused on developing active chevron technology for the bypass nozzle of a similar engine simulator by detailed study of individual chevrons. This concept cannot be extended to the core engine nozzle at the present time because of temperature limitations of commercial SMA materials. 


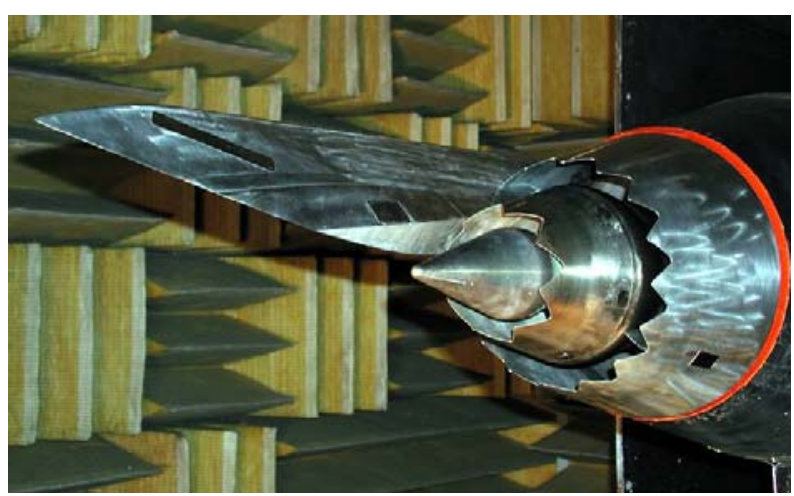

Figure 1: Static chevron scale model nozzle.

Previous work demonstrated the feasibility of flat, active chevrons, i.e., without the cylindrical radius of curvature ${ }^{[24],[25]}$. The SMAHC material system consisted of glass-epoxy unidirectional pre-impregnated (pre-preg) tape and Nitinol ribbon (rectangular cross-section wire). The requirements for electrical activation of the SMA actuators and for an aerodynamically clean trailing edge of minimum thickness mandated electrical continuity of the actuator(s) within the chevron and actuator ingress/egress points at the chevron root. These constraints were accommodated in the fabrication approach by incorporating joints between two layers of Nitinol within the laminate to provide for electrical continuity.

The proper bending deformation was enabled for flat chevrons by simply embedding the actuators on one side of the middle surface of the laminate. However, special consideration must be taken for a curved chevron, shown schematically in Figure 2. These comments are supported by the following discussion. Beam theory, although not rigorously applicable in this case, gives the correct mechanical trends and will be used for illustration. The neutral axis of a beam of arbitrary cross-section geometry coincides with the centroidal axis. These axes are coincident with the centerline of the middle surface for a beam with a rectangular cross section and uniform or symmetric material distribution. The neutral axis for a beam with a curved cross section lies on the concave side of the middle surface, as illustrated in Figure 2. The offset of the neutral axis from the middle-surface centerline varies with axial/longitudinal position for a tapered, curved-section beam, i.e., a beam with a curved cross section of varying arc length like that of the curved chevron. Asymmetric material distribution also affects the location of the neutral axis because of the varying modulus. This effect is temperature dependent for embedded SMA materials because of the temperature dependent modulus. However, the effect is rather small for the present case and will be neglected in this discussion because the SMA content is small and the modulus ratio is small.

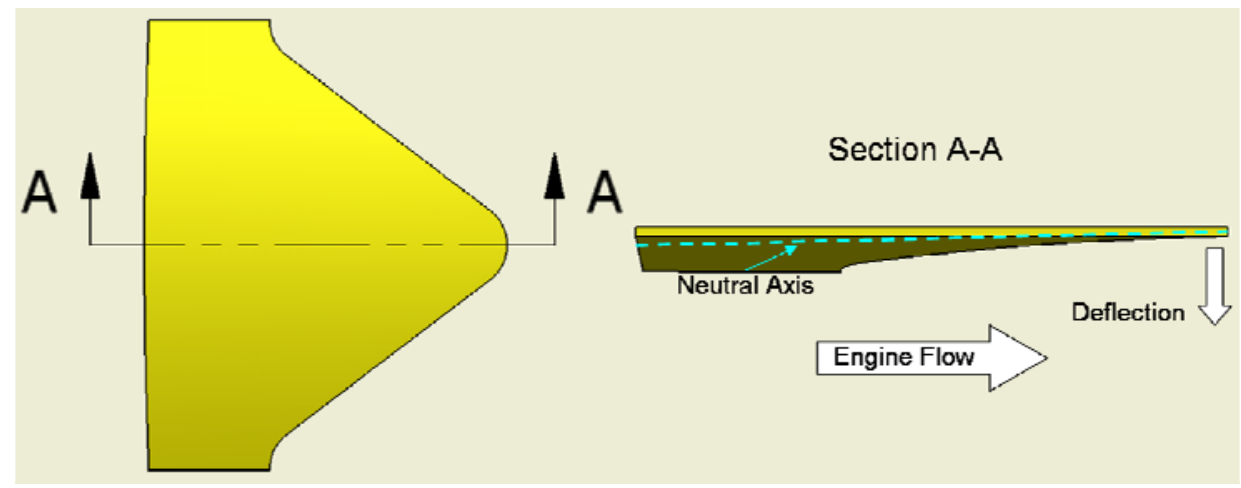

Figure 2: Schematic of curved active chevron.

Recent work at NASA LaRC extended the active chevron concept above to include the cylindrical radius of curvature ${ }^{[29]}$. Two curved, active chevron concepts were devised to achieve the desired bending functionality, with other geometric features (e.g., unsupported length and aspect ratio) consistent with the flat design. One concept involves angling the actuator assemblies such that the actuation force is positioned below the neutral axis over the entire length of the chevron. This concept is shown schematically by the middle surface in Figure 3 and it is understood that the actuators, indicated in red, are embedded below the middle surface in the laminate. This configuration is retracted from the flow in 
the un-powered (non-actuated) state and will be referred to as the power-off-retracted (POR) concept. The other concept involves reversing the sense of the actuation such that power (actuation) is required to retract the chevron from the flow, termed the power-off-immersed (POI) concept. The POI chevron is immersed in the non-actuated state, demonstrated by the middle surface shown in Figure 4, and it is understood that the actuators, indicated in red, are embedded above the middle surface in the laminate. The as-fabricated tip immersion of the POI chevron was specified to be $0.203 \mathrm{~cm}$ to give "headroom" in anticipation of flow loading reducing the un-powered immersion and is the maximum that numerical models indicated could be retracted by the dual-actuator design.

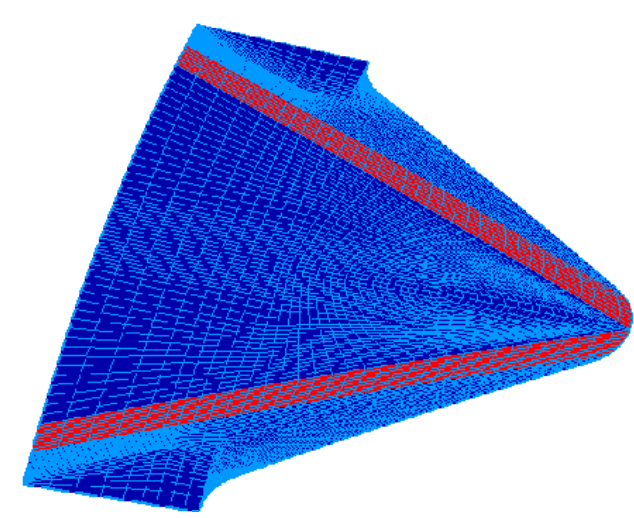

Figure 3: Configuration and mesh for POR active chevron.

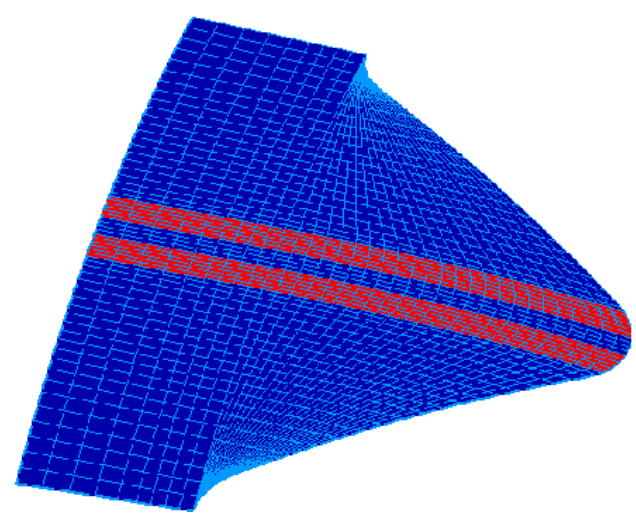

Figure 4: Configuration and mesh for POI active chevron.

A chevron of each type was subjected to 55 thermal cycles in a bench-top configuration, thereby rendering the SMAHC structures thermomechanically stable as the actuators are trained in situ. The bench-top test results showed that the POI chevron had a much greater deflection range than the POR chevron on the first thermal cycle, but with a commensurately greater permanent deformation such that the stabilized deflection range was similar between the two chevron types. The permanent deformation, resulting from hysteresis in the actuators and creep in the glass-epoxy matrix ${ }^{[30]}$, accumulated primarily over the first few cycles and stabilized. The permanent deformation left the POR chevron slightly immersed and the POI chevron less immersed than planned subsequent to the bench-top tests.

\section{TESTING WITH REPRESENTATIVE FLOW}

\subsection{Experimental arrangement}

Prototypes of the two chevron types were tested in the Small Anechoic Jet Facility (SAJF) at NASA LaRC. The test apparatus consisted of the SAJF apparatus, the chevron/nozzle assembly, a digital infrared (IR) camera, a projection moiré interferometry (PMI) system, a laser displacement transducer (LDT), and a control and data acquisition system interfaced with the chevron instrumentation and a DC power supply. A schematic of the overall SAJF test configuration is shown in Figure 5. The SAJF apparatus consisted of a heated and pressurized air supply system that provided controlled flow conditions to a nozzle assembly, which entrained flow about the supply duct and exhausted into a semianechoic test cell. A flow collector and exhaust duct/fan system nominally maintained ambient temperature and pressure conditions in the test cell.

The IR and PMI cameras were configured on an optical bench within the test cell at a distance of approximately $53.3 \mathrm{~cm}$ and $81.3 \mathrm{~cm}$ from the chevron, respectively. The PMI camera had a field of view of $7.30 \times 5.72 \mathrm{~cm}$ (width $\times$ height), with a spatial resolution of $5.39 \mathrm{e}-3 \mathrm{~cm}$, and the video was digitized to 8 bits. The IR camera had a field of view of $22.68 \times 16.90 \mathrm{~cm}$ with a spatial resolution of $0.07 \mathrm{~cm}$ and a measurement range of $0-500^{\circ} \mathrm{C}$ with a temperature resolution of $0.03^{\circ} \mathrm{C}$. The LDT was mounted to a bracket attached to the nozzle assembly that positioned the laser impingement location at approximately $0.102 \mathrm{~cm}$ from the chevron tip. The LDT had a measurement range of $3 \mathrm{~cm}$ and a resolution of $3 \mu \mathrm{m}$. 


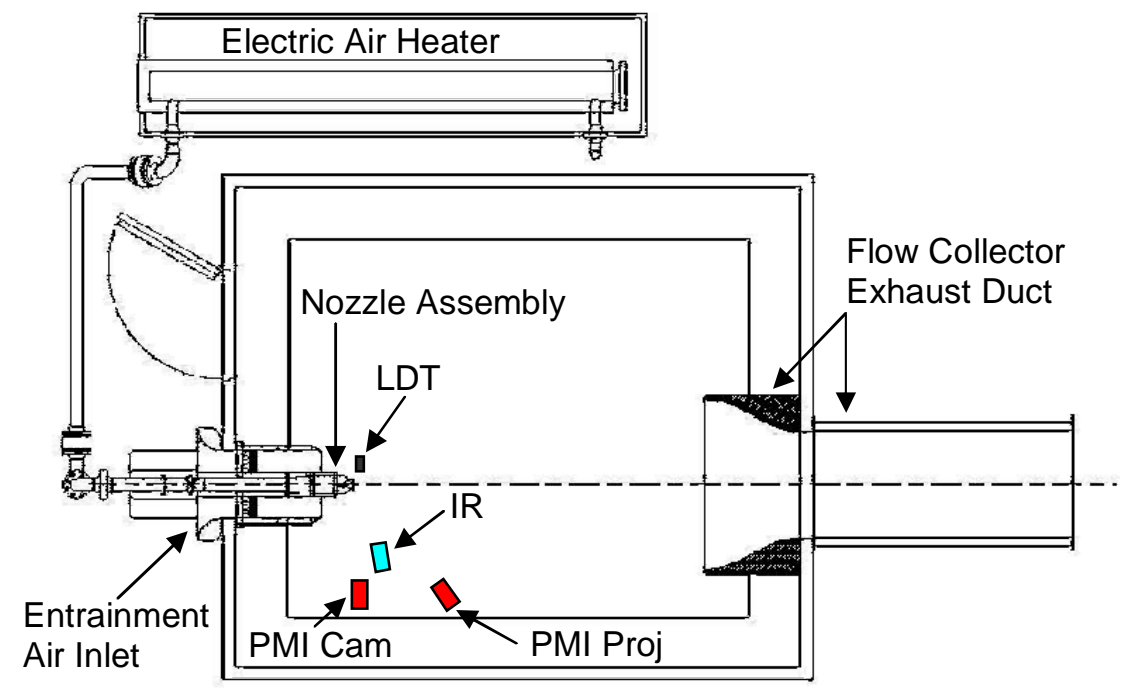

Figure 5: Top-view schematic of the SAJF test configuration.

Details of the chevron and nozzle assembly are shown in Figure 6. The POR chevron is shown for illustration. The POI test configuration was analogous. Progressing in the flow direction, from left to right in the photo, the nozzle assembly consisted of a round $(15.24 \mathrm{~cm}$ diameter) to square transition piece and a $5.08 \times 5.08 \mathrm{~cm}$ square nozzle. The chevron and stainless steel adapter assembly was mounted to the square nozzle. A three-sided nozzle extension provided the other three sides of flow containment over the length of the adapter. Each chevron was instrumented with a pair of back-toback strain gages, i.e., gages mounted at the same planform location but on opposite sides of the chevron. The gages were located on the centerline of the POR chevron and at an outboard location, below the centerline in Figure 6, for the POI chevron. The gages were mounted close to the support (adapter) in both cases. A type-T thermocouple was mounted in the vicinity of and at the mid-span of the gage length of each strain gage. The thermocouples were mounted above/below the respective strain gages for the POR/POI chevron when oriented as shown in Figure 6 . The instrumentation is not visible in the figure because both chevron surfaces had been painted with flat, white enamel paint to provide an opaque and diffuse surface for the PMI and LDT measurements. The paint gave a total hemispherical emissivity of 0.9 for calibration of the IR measurements.

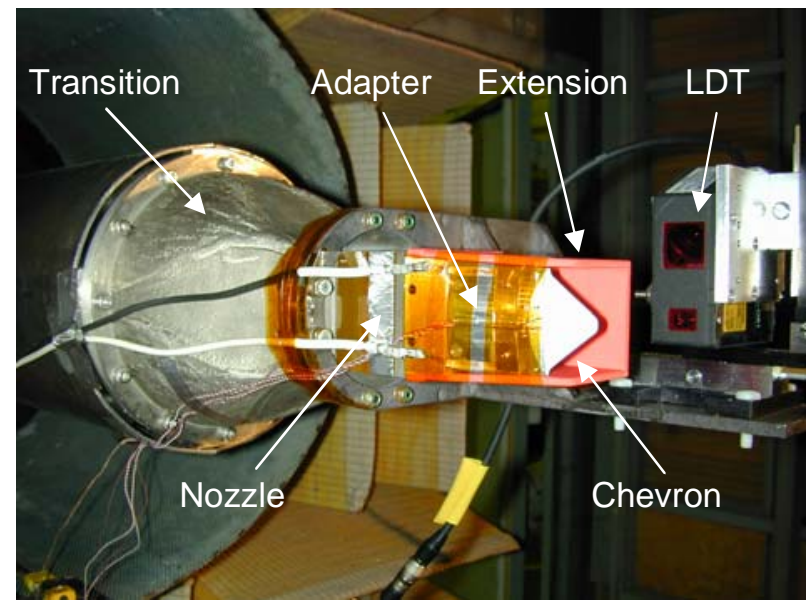

Figure 6: Detail of chevron-adapter assembly, nozzle, and transition to supply duct.

The SMA actuators were configured electrically in series by connections in the adapter and joints within the chevron. Electrical power was supplied to the chevron by a DC power supply operated in constant current mode and commanded by analog voltage from the control system with input from the strain, thermocouple, LDT, and flow instrumentation. The flow measurements included total and ambient temperature and pressure. Heating of the actuators was done in 
either an open-loop or closed-loop mode. In open-loop mode, a specified current level was applied to the actuators to study the relationship between applied power, chevron temperature, and chevron immersion. The chevron temperature metric was taken via the IR camera as the average along the centerline of the top actuator assembly, as viewed in Figure 6. The maximum allowed current in each case was defined as that required to achieve a set-point temperature of $121.1^{\circ} \mathrm{C}$. In closed-loop mode, a proportional-integral controller with anti-windup, see Cabell et al. ${ }^{[31]}$, was used to regulate the current applied to the actuators in order to drive the chevron to a specified tip immersion. The output of the LDT was used for the feedback measurement in closed-loop mode.

\subsection{Experimental results}

Recall that this study is focused on simulated bypass flow conditions because of the temperature limitations of commercially available SMAs. The test conditions shown in Table 1 were established as representative of the bypass flow environment of desirable engine configurations, i.e., bypass ratios (BPRs) 5 and 8, at take-off (TO) and climb (CB) conditions. Terms in the table include nozzle pressure ratio (NPR), total temperature $\left(\mathrm{T}_{t}\right)$, total pressure $\left(\mathrm{P}_{t}\right)$, Mach number/temperature/velocity according to ideal gas relations $\left(\mathrm{M}_{\text {ideal }} / \mathrm{T}_{\text {ideal }} / \mathrm{V}_{\text {ideal }}\right)$, and the adiabatic wall temperature $\left(\mathrm{T}_{\text {aw }}\right)$ assuming turbulent flow conditions. Other quantities needed to produce the tabulated quantities are the ideal gas constant $287 \mathrm{~m}^{2} /\left(\mathrm{s}^{2} \cdot \mathrm{K}\right)$, specific heat ratio of 1.4 , flow area of $25.8 \mathrm{~cm}^{2}$, and ambient pressure of $101.36 \mathrm{kPa}$. Although flow at a higher total temperature, e.g., of $82.2^{\circ} \mathrm{C}$, is more representative of actual bypass nozzle flow conditions, flow at a total temperature of $26.7^{\circ} \mathrm{C}$ is the focus of this study because heat transfer between the flow and the chevron is governed by $\mathrm{T}_{\mathrm{aw}}$ and the austenite start temperature for the Nitinol alloy used in this study is $45^{\circ} \mathrm{C}$. Thus, the $26.7^{\circ} \mathrm{C}$ flow enables the entire chevron actuation authority to be effected by control stimulus and the low-temperature flow is expected to have negligible effect on the jet noise simulation.

Table 1: Flow parameters associated with the tests performed in the SAJF.

\begin{tabular}{|c|c|c|c|c|c|c|c|c|c|}
\hline Test Point & NPR & $\mathrm{T}_{\mathrm{t}},{ }^{\circ} \mathrm{C}$ & $\mathrm{M}_{\text {ideal }}$ & $\mathrm{P}_{\mathrm{t}}, \mathrm{kPa}$ & $\mathrm{T}_{\text {ideal }},{ }^{\circ} \mathrm{C}$ & $\mathrm{V}_{\text {ideal }}, \mathrm{m} / \mathrm{s}$ & Flow, $\mathrm{kg} / \mathrm{s}$ & $\mathrm{T}_{\mathrm{aw}},{ }^{\circ} \mathrm{C}$ & Comments \\
\hline 1 & 1.46 & 26.7 & 0.756 & 147.98 & -4.1 & 248.5 & 0.841 & 23.3 & BPR 8, CB \\
\hline 2 & 1.62 & 26.7 & 0.860 & 164.20 & -11.9 & 278.6 & 0.972 & 22.4 & BPR 8, TO \\
\hline 3 & 1.75 & 26.7 & 0.931 & 177.37 & -17.6 & 298.4 & 1.064 & 21.8 & BPR 5, TO \\
\hline
\end{tabular}

A typical test in the SAJF consisted of the following. A run without flow was performed first in each case to serve as a baseline. Then, flow was established at a constant total temperature and total pressure was controlled to successively achieve each of the NPR settings in Table 1 in either ascending or descending order. Open- and/or closed-loop chevron runs were conducted with constant NPR at each of the settings in a test. Performance data associated with each of the chevron runs included the LDT, strain, thermocouple, flow, and IR thermography data collected throughout the run and PMI data (50-frame averages) collected at specific conditions of interest within the run.

General comments on these tests follow. Recall that the POR/POI chevron is actuated to immerse/retract. Active immersion of the POR chevron is resisted and passive retraction is aided by the flow. Conversely, passive immersion of the POI chevron is resisted and active retraction is aided by the flow. It is apparent that the POR concept is implicitly advantageous for the application because closed-loop control enables the chevron to be immersed independent of flow and other parameters, given adequate control authority. In contrast, immersion of the POI chevron must be "designed in" and is flow dependent. The aerodynamic load also tends to remove the permanent deformation in the POR chevron, whereas it exacerbates the immersion loss for the POI chevron.

The permanent deformation associated with the POR chevron decreased with increasing NPR and was eliminated at the highest NPR setting of 1.75. The tip deflection versus time for the POR and POI chevron is shown in Figure 7 and Figure 8, respectively, each corresponding to actuation to the $121.1^{\circ} \mathrm{C}$ set-point temperature in the presence of flow at the 1.75 NPR setting. The direction (sign) of the deflection for one of the two chevrons was inverted to make them consistent and the starting position for each has been assigned a value of zero for comparison purposes. Power is initiated at just after one minute in both cases and removed at approximately 3.3 and 3.7 minutes, respectively. It can be seen that the POR chevron exhibited slightly greater deflection range under the aerodynamic load as compared to the POI chevron, which was mainly attributable to the permanent deformation and flow effects described above. The effects of flow were also evident in the rapid and repeatable immersion and retraction of the POR chevron, the latter coming as a 
result of the compatible effects of the aerodynamic load (AL) and structural restoring force (RF). The POI chevron exhibited a two-stage immersion after the power-off event. Initial rapid movement, due to the elastic portion of the restoring force, was followed by a slow and asymptotic finish from relaxation of plasticity (creep recovery, CR) in the restoring force working against the flow. It is clear from all of the above observations that the POR chevron concept is the better candidate for the application. However, the POR chevron prototype did not meet the immersion objective with flow, only achieving approximately 0.08 of the desired $0.127 \mathrm{~cm}$ of tip deflection. It was expected that fabrication and design changes would remedy the performance issue as described in the next section.

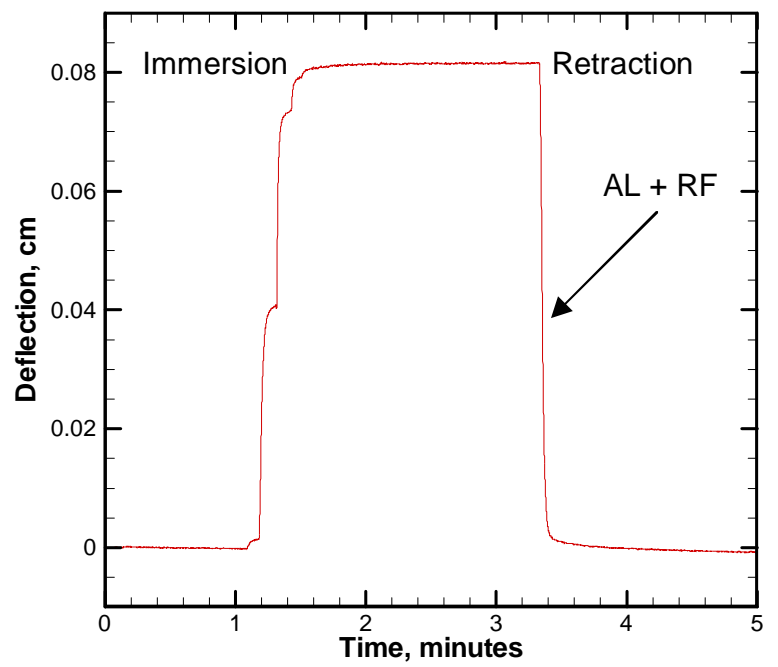

Figure 7: Tip deflection for the POR chevron at 1.75 NPR.

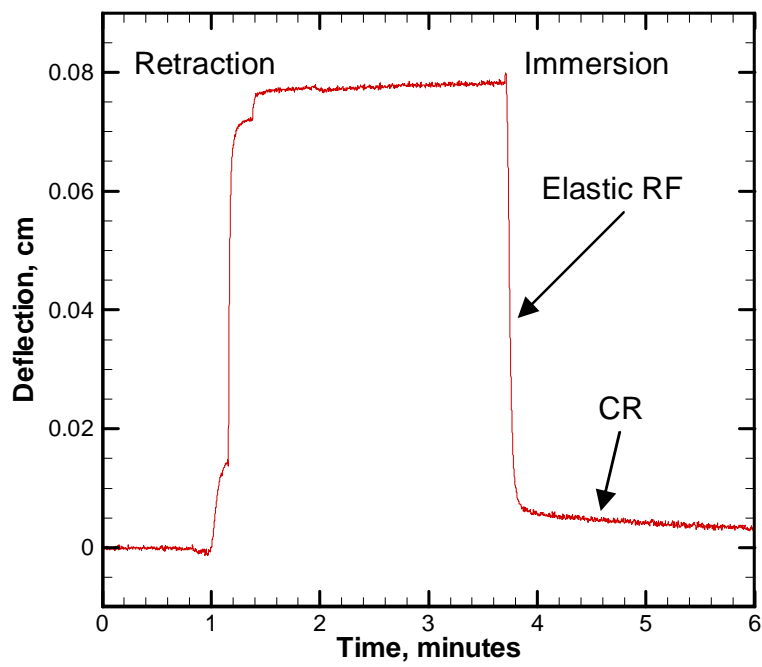

Figure 8: Tip deflection for the POI chevron at 1.75 NPR.

\section{POR CHEVRON CHANGES}

The general fabrication process that was employed in previous work and in this study consisted of lamination of oversized pre-preg layers, consolidation by vacuum hot press, and machining to final dimensions. The glass-epoxy material was an S2-glass $/ 3501-6$ resin system with a nominal cured ply thickness of $0.01 \mathrm{~cm}$. The Nitinol ribbon had nominal cross-sectional dimensions of $0.229 \times 0.015 \mathrm{~cm}$ and transformation temperatures, as determined by differential scanning calorimetry, of $\mathrm{A}_{\mathrm{s}}=45^{\circ} \mathrm{C}, \mathrm{A}_{\mathrm{f}}=60^{\circ} \mathrm{C}, \mathrm{M}_{\mathrm{s}}=17^{\circ} \mathrm{C}$, and $\mathrm{M}_{\mathrm{f}}=0^{\circ} \mathrm{C}$. The Nitinol ribbon material was prestrained (elongated) $4 \%$ and lightly sandblasted. Pairs of the Nitinol ribbon were aligned and joined at a location along the length that was convenient for placement at the intended chevron tip during the lamination process.

Details of the original POR fabrication process are given in Turner et al. ${ }^{[29]}$. The mold for the POR chevron type is shown in Figure 9 and was designed to allow for a range of chevron aspect ratios. Lamination of the POR chevron was performed according to the sequence (+45/SMA/-45/SMA/90/-45/+45), which positioned the actuators on the concave side of the laminate middle surface. The angled actuator assemblies were constrained at both ends of the mold such that a cross-over occurred within the part, as shown in Figure 10. This cross-over location was $0.030 \mathrm{~cm}$ (2 layers of Nitinol) thicker than any other location in the part. The thickness discontinuity was accommodated in the original procedure by inserting a $0.318 \mathrm{~cm}$-thick layer of RTV casting compound on top of the laminate and beneath the mold top. The flexible layer had the adverse effect of allowing the actuators to push the overlying pre-preg up during consolidation, thereby creating ridges on the convex side of the chevron and reducing the authority of the actuators because of their movement toward the neutral axis. This effect was remedied by deleting the flexible layer from the process and inserting layers of polyimide film, with a combined thickness of $0.030 \mathrm{~cm}$ and a strategic hole at the actuator cross-over location, on the concave side of (beneath) the laminate to accommodate the thickness discontinuity. This procedural change resulted in a consolidated part with excellent thickness uniformity, varying by no more than $0.008 \mathrm{~cm}$, except for a bulge on the concave side at the cross-over location. Pictures of the flexible and polyimide layers are illustrated in Figure 11 and Figure 12, respectively. 


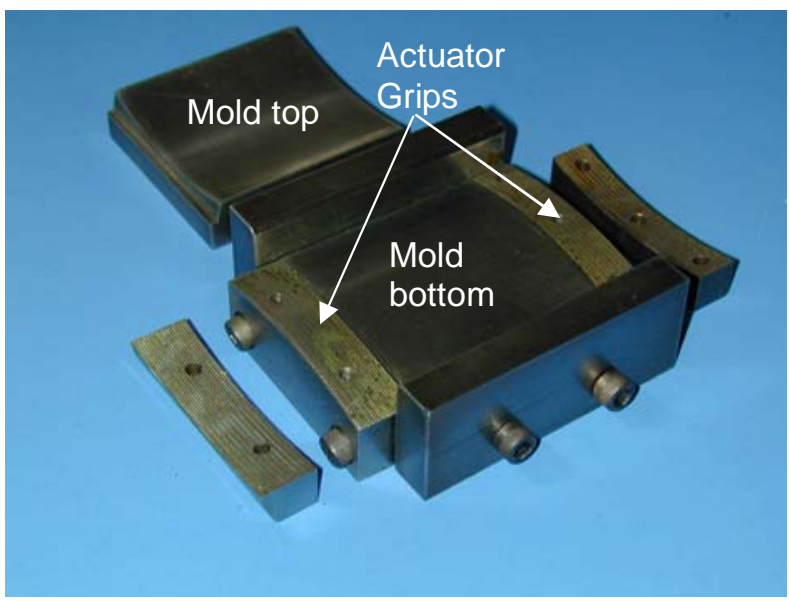

Figure 9: Mold for the POR chevron type.

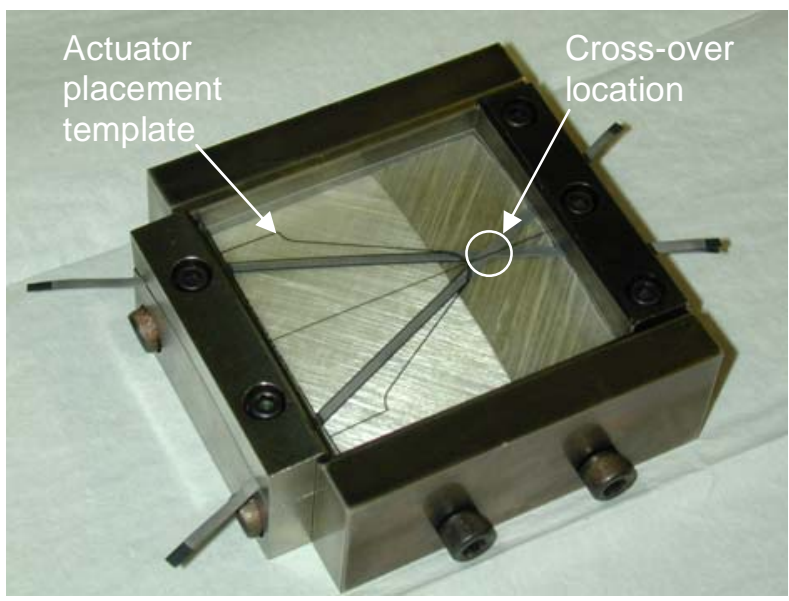

Figure 10: POR lay-up in mold showing actuator cross-over.

The POR chevron design was further altered to increase the aspect ratio by increasing the unsupported length from 2.654 to $3.175 \mathrm{~cm}$, leaving the width and other dimensions unchanged. The new aspect ratio was within the range of known acceptable chevron planform configurations and was expected to have no negative effects while gaining mechanical advantage for increased immersion capability. The new chevron geometry was termed the "1.25" POR chevron and was assembled according to the new procedure. The laminate was cured according to the cycle recommended by the prepreg manufacturer. The Nitinol leads at the root edge of the consolidated laminates were copper plated to improve contact-type electrical connections. The consolidated laminate was installed in a matching trim tool that applied clamping pressure for machining to net shape. The laminate-tool assembly was installed in a vice that was secured to the table of a milling machine, as shown in Figure 13. Additional clamping pressure was applied via a strap clamp near the trim-tool tip to prevent delamination at the actuator locations during machining. The chevron laminate was machined to net shape by passing a $0.3175 \mathrm{~cm}$, 4-flute, carbide end mill around the net chevron shape while running at 10,000 revolutions per minute. The end mill made multiple passes, cutting approximately $0.013 \mathrm{~cm}$ through the thickness during each pass. Flood coolant was applied during the entire machining process. An example of a POR chevron resulting from this machining process is shown in Figure 14.

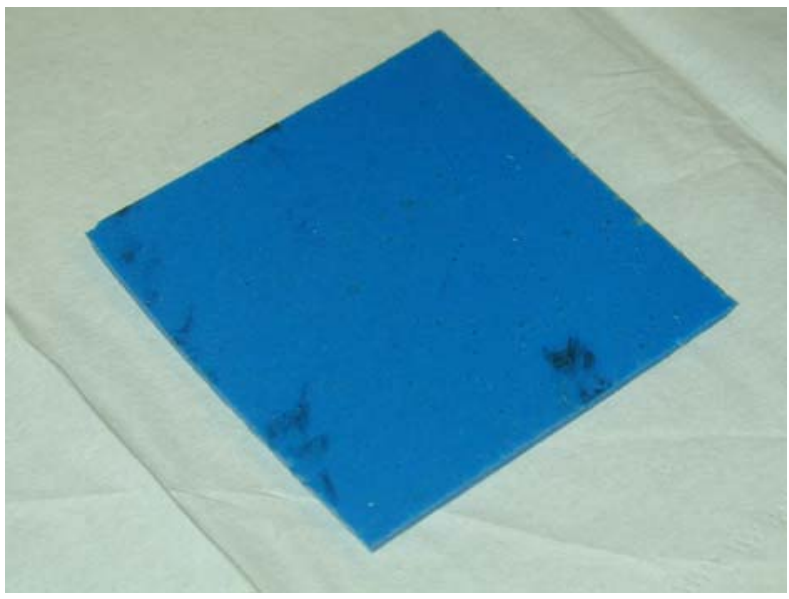

Figure 11: Flexible layer for thickness discontinuity.

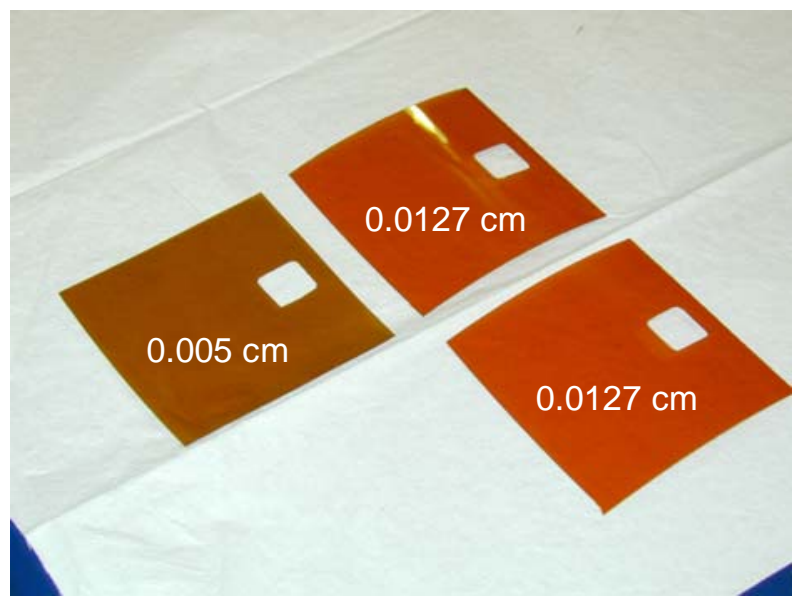

Figure 12: Polyimide layers for thickness discontinuity.

Although the laminate was asymmetric due to the embedded Nitinol ribbon, no warping occurred after cure because the restraint on the actuators prevents recovery of the prestrain and participation in generation of a thermal moment during cooling. The " 1.25 " POR chevron exhibited a thickness of $0.058 \mathrm{~cm}$ and $0.066 \mathrm{~cm}$ in regions without and with the embedded Nitinol, respectively, and was uniform to $\pm 0.001 \mathrm{~cm}$ within a given region. The thickness difference between the two regions was shared on both sides of the laminate. 


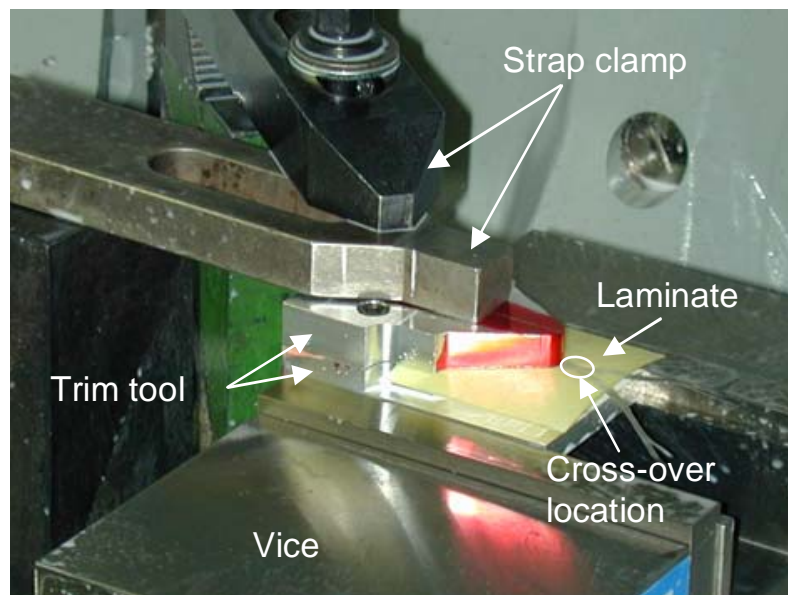

Figure 13: Laminate-tool assembly in milling machine.

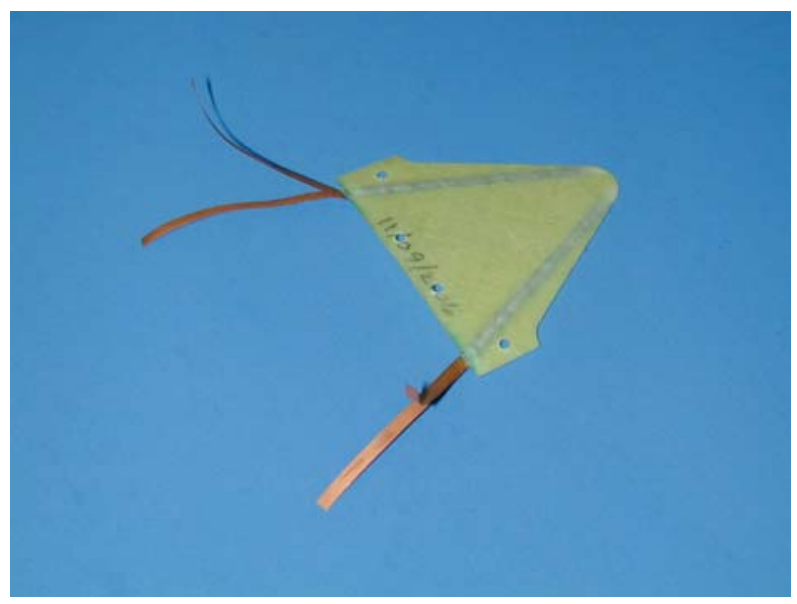

Figure 14: Finished "1.25” POR chevron.

\section{REFINED POR CHEVRON WITH FLOW}

A "1.25" POR chevron resulting from the new fabrication procedure was again tested in the SAJF. It was put through 53 thermal cycles without flow to stabilize the thermomechanical performance. The tests without flow were conducted via a thermal controller that used the centerline average temperature of an actuator as the control metric. The stabilized deflection performance over a thermal cycle is shown in Figure 15. It can be seen that the chevron achieved a maximum tip deflection of almost $0.2 \mathrm{~cm}$ and a deflection range of approximately $0.13 \mathrm{~cm}$ with a permanent deflection offset of approximately $0.07 \mathrm{~cm}$.

Testing with flow was conducted in the same manner as that described previously, except only open-loop runs were performed. The tip deflection versus time at each of the three NPR settings is shown in Figure 16. The flow was brought to a steady-state condition at each NPR and the chevron was driven with the current necessary to achieve the $121.1^{\circ} \mathrm{C}$ set-point temperature. It can be seen that the amount of permanent deformation decreased with increasing NPR, with a majority of it being removed at the highest NPR of 1.75. The deflection range decreased slightly with increasing NPR, leaving approximately $0.112 \mathrm{~cm}$ of deflection range at the $1.75 \mathrm{NPR}$. Note that the actual chevron tip deflection is greater than these reported values because the LDT measurement location was short of the tip, by approximately 0.127 $\mathrm{cm}$ in the case of the " 1.25 " POR chevron.

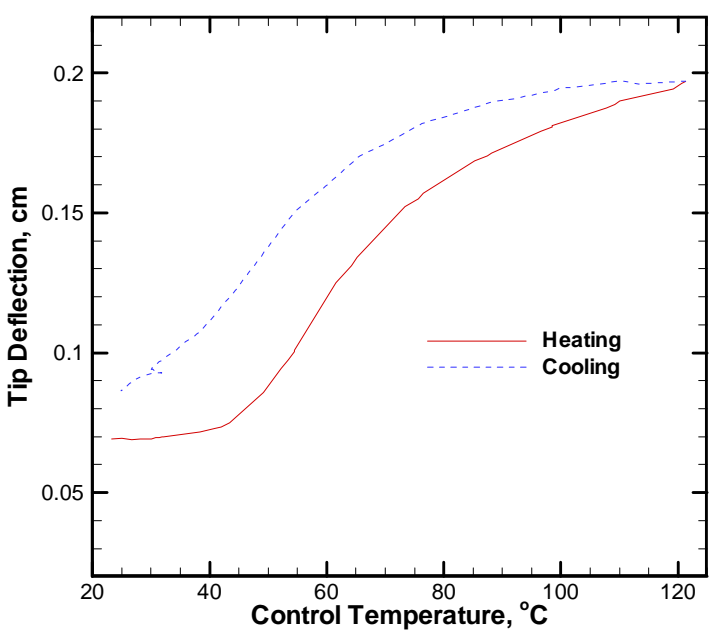

Figure 15: Stabilized tip deflection of the "1.25" POR chevron without flow.

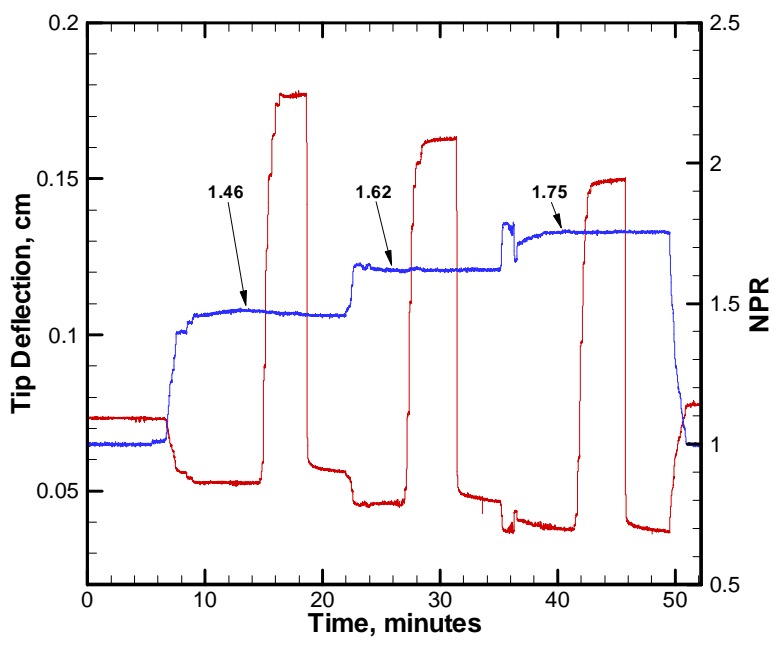

Figure 16: Tip deflection of the "1.25" POR chevron during actuation at three NPR settings. 


\section{SUMMARY AND CONCLUSIONS}

A novel approach for development of an active chevron for jet noise reduction has been developed based upon shape memory alloy hybrid composite (SMAHC) technology. Two active chevron concepts were previously devised to achieve the desired functionality, one that was termed power off retracted (POR) and one that was termed power off immersed (POI). Prototypes of each chevron type were fabricated from glass-epoxy pre-preg and Nitinol ribbon actuator assemblies by a vacuum hot press approach.

The chevron prototypes were tested with flow conditions representative of the bypass exhaust of typical commercial jet engines. The aerodynamic load was found to diminish the performance of the POI chevron more than the POR. This difference was attributed to the fact that the POR actuation scheme is more suited to precise immersion control because the chevron works against the aerodynamic load to immerse and the aerodynamic load aids in retraction. The POR chevron was found to exhibit very rapid and repeatable response and greater deflection range than the POI chevron because of these factors. Although neither original chevron prototype achieved the deflection performance objective with flow, the POR chevron was selected for further development because of its advantages.

A flaw in the fabrication approach for the POR chevron was discovered that allowed the actuators to move in an unfavorable fashion during consolidation. The fabrication approach was altered to mitigate this problem. The new fabrication approach produced chevrons with improved thickness uniformity within a given chevron and better repeatability between chevrons. The aspect ratio of the POR chevron was increased (the chevron was lengthened) in order to achieve additional deflection gain by mechanical advantage. The new POR chevron was also tested with representative flow and the deflection response nominally achieved the performance objectives. Additional work is underway with the new POR chevron prototype to finalize its design and to build an entire engine assembly for testing in the NASA LaRC Low Speed Aeroacoustic Wind Tunnel (LSAWT).

\section{ACKNOWLEDGEMENTS}

The authors gratefully acknowledge the contributions of the following colleagues: George Hilton (NASA LaRC) for assistance in chevron fabrication, test system development and data collection; Mark Cagle (NASA LaRC) for assistance in design of fabrication and test hardware; Sean Britton (NASA LaRC) for assistance in chevron fabrication; Alan Scheidegger (NASA LaRC) for chevron and test hardware machining; Gary Fleming and Felecia Berry (NASA LaRC) for PMI data collection and processing; Larry Becker and Brian Howerton (Lockheed Martin) for development of the LabVIEW-based thermal controller and data acquisition system; Mark Roth (Modern Machine and Tool Company, Inc.) for test hardware preparation; and Rick Young (NASA LaRC) for helpful technical discussions.

\section{REFERENCES}

[1] Saiyed, N. H., Mikkelsen, K. L., and Bridges, J. E., "Acoustics and Thrust of Separate-Flow Exhaust Nozzles with Mixing Devices for High-Bypass-Ratio Engines," $6^{\text {th }}$ AIAA/CEAS Aeroacoustics Conference, AIAA Paper 20001961, Lahaina, HI, 2000.

[2] Thomas, R. H., Kinzie, K. W., and Pao, S. P., "Computational Analysis of a Pylon-Chevron Core Nozzle Interaction," $7^{\text {th }}$ AIAA/CEAS Aeroacoustics Conference, AIAA Paper 2001-2185, Maastricht, The Netherlands, 2001.

[3] Callender, B., Gutmark, E., and Martens, S., "A Near-Field Investigation of Chevron Nozzle Mechanisms," $9^{\text {th }}$ AIAA/CEAS Aeroacoustics Conference and Exhibit, AIAA Paper 2003-3210, Hilton Head, SC, 2003.

[4] Massey, S. J., Thomas, R. H., Abdol-Hamid, K. S., and Elmiligui, A. A., "Computational and Experimental Flow Field Analyses of Separate Flow Chevron Nozzles and Pylon Interaction," $9^{\text {th }}$ AIAA/CEAS Aeroacoustics Conference and Exhibit, AIAA Paper 2003-3212, Hilton Head, SC, 2003.

[5] Rask, O., Gutmark, E., and Martens, S., "Acoustic Investigation of a High Bypass Ratio Separate Flow Exhaust System," 42 ${ }^{\text {nd }}$ AIAA Aerosciences Meeting and Exhibit, AIAA Paper 2004-9, Reno, NV, 2004.

[6] Koch, L. D., Bridges, J., and Khavaran, A., "Mean Flow and Noise Prediction for a Separate Flow Jet with Chevron Mixers," $42^{\text {nd }}$ AIAA Aerosciences Meeting and Exhibit, AIAA Paper 2004-189, Reno, NV, 2004.

[7] Callender, B., Gutmark, E., and Martens, S., "A PIV Flow Field Investigation of Chevron Nozzle Mechanism," $42^{\text {nd }}$ AIAA Aerosciences Meeting and Exhibit, AIAA Paper 2004-191, Reno, NV, 2004. 
[8] Bridges, J. and Brown, C. A., "Parametric Testing on Chevrons on Single Flow Hot Jets," $10^{\text {th }}$ AIAA/CEAS Aeroacoustics Conference, AIAA Paper 2004-2824, 2004.

[9] Doty, M. J., Henderson, B. S., and Kinzie, K. W., "Turbulent Flow Field Measurements of Separate Flow Round and Chevron Nozzles with Pylon Interaction Using Particle Image Velocimetry," $10^{\text {th }}$ AIAA/CEAS Aeroacoustics Conference, AIAA Paper 2004-2826, 2004.

[10] Callender, B., Gutmark, E., and Martens, S., "Far-Field Acoustic Investigation into Chevron Nozzle Mechanisms and Trends," AIAA Journal, 43(1), 87-95 (2005).

[11] Mengle, V. G., "Relative Clocking of Enhanced Mixing Devices for Jet Noise Benefit," $43^{\text {rd }}$ AIAA Aerospace Sciences Meeting and Exhibit, AIAA Paper 2005-996, Reno, NV, 2005.

[12] Mengle, V. G., "Jet Noise Characteristics of Chevrons in Internally Mixed Nozzles," $11^{\text {th }}$ AIAA/CEAS Aeroacoustics Conference, AIAA Paper 2005-2934, Monterey, CA, 2005.

[13] Otsuka, K. and Wayman, C. M., Shape Memory Materials, Cambridge University Press, New York, NY, 1998.

[14] Bruck, H. A., Moore, C. L., and Valentine, T. L., "Repeatable Bending Actuation in Polyurethanes Using Opposing Embedded One-Way Shape Memory Alloy Wires," Smart Mater. Struct., 11(4), 509-518 (2002).

[15] Kim, C., Park, B.-S., and Goo, N.-S., "Shape Changes by Coupled Bending and Twisting of Shape-Memory-AlloyEmbedded Composite Beams," Smart Mater. Struct., 11(4), 519-526 (2002).

[16] Chandra, R., "Active Shape Control of Composite Blades Using Shape Memory Actuation," Smart Mater. Struct., 10(5), 1018-1024 (2001).

[17] Baz, A., Chen, T., and Ro, J., "Shape Control of NITINOL-Reinforced Composite Beams," Composites: PartB, 31(8), 631-642 (2000).

[18] Calkins, F. T. and Butler, G. W., "Subsonic Jet Noise Reduction Variable Geometry Chevron," 42 ${ }^{\text {nd }}$ AIAA Aerospace Sciences Meeting and Exhibit, AIAA Paper 2004-0190, Reno, NV, 2004.

[19] Mabe, J. H., Ruggeri, R. T., Butler, G. W., and Sellmeyer, S., "Morphing Chevrons for Take Off and Cruise Noise Reduction," The 2004 International Symposium on Active Control of Sound and Vibration (ACTIVE 2004), INCE/USA, Williamsburg, VA, 2004.

[20] Mabe, J. H., Cabell, R. H., and Butler, G. W., "Design and Control of a Morphing Chevron for Takeoff and Cruise Noise Reduction," $11^{\text {th }}$ AIAA/CEAS Aeroacoustics Conference, AIAA Paper 2005-2889, Monterey, CA, 2005.

[21] Turner, T. L., "Thermomechanical Response of Shape Memory Alloy Hybrid Composites," NASA/TM-2001210656, 2001.

[22] Turner, T. L., Lach, C. L., and Cano, R. J., "Fabrication and Characterization of SMA Hybrid Composites," in Smart Structures and Materials 2001: Active Materials: Behavior and Mechanics, C. S. Lynch (Editor) Proceedings of SPIE Vol. 4333, 343-354 (2001).

[23] Turner, T. L., "Structural Acoustic Response of a Shape Memory Alloy Hybrid Composite Panel (Lessons Learned)," in Smart Structures and Materials 2002: Smart Structures and Integrated Systems, L. P. Davis (Editor), Proceedings of SPIE Vol. 4701, 592-603 (2002).

[24] Turner, T. L., Buehrle, R. D., Cano, R. J., and Fleming, G. A., "Modeling, Fabrication, and Testing of a SMA Hybrid Composite Jet Engine Chevron Concept," J. of Intell. Matl. Systems and Struct., 17(6), 483-497(2006).

[25] Turner, T. L., Cabell, R. H., Cano, R. J., and Fleming, G. A., "Design, Fabrication, and Testing of a SMA Hybrid Composite Jet Engine Chevron," AIAA Journal, submitted December 2007.

[26] Turner, T. L., "A New Thermoelastic Model for Analysis of Shape Memory Alloy Hybrid Composites," J. of Intelligent Matl. Systems and Structures, 11(5), 382-394 (2000).

[27] Turner, T. L. and Patel, H. D., "Input Files and Procedures for Analysis of SMA Hybrid Composite Beams in MSC.Nastran and ABAQUS," NASA/TM-2005-213517, January 2005.

[28] Turner, T. L. and Patel, H. D., "Analysis of SMA Hybrid Composite Structures in MSC.Nastran and ABAQUS," J. of Intelligent Matl. Systems and Structures, 18(5), 435-447 (2007).

[29] Turner, T. L., Cabell, R. H., Cano, R. J., and Silcox, R. J., "Development of a SMA hybrid composite jet engine chevron concept," in Active and Passive Smart Structures and Integrated Systems 2007, edited by Y. Matsuzaki, M. Ahmadian, and D. Leo, Proc. of SPIE Vol. 6525, 65250J (2007).

[30] Dowling, N. E., Mechanical Behavior of Materials, $2^{\text {nd }}$ Edition, Prentice Hall, Inc., NJ, $43-44$ (1999).

[31] Cabell, R. H., Schiller, N. H., Mabe, J. H., Ruggeri, R. T., and Butler, G. W., "Feedback Control of a Morphing Chevron for Takeoff and Cruise Noise Reduction," The 2004 International Symposium on Active Control of Sound and Vibration (ACTIVE 04), INCE/USA, Williamsburg, VA, 20-22 September 2004. 